\title{
Dynamic analysis of the box girder bridge for biaxial rubber-tired Light
}

\section{Rail Transit}

\author{
Jia-jian Zhao, a \\ ${ }^{1}$ College of Urban Construction, Zhongkai Univ. of Agriculture and Engineering, Guangzhou, \\ Guangdong, 510225, China \\ azjjjames@163.com
}

Keywords: Box girder bridge, Dynamic response, Biaxial rubber-tired LRT.

Abstract. According to train-bridge system spatial vibration equation and Newmark- $\beta$ stepwise integration method, the dynamic response of the box girder bridge for biaxial rubber-tired Light Rail Transit (LRT) was calculated and analyzed. The dynamic analysis results show that the box girder bridge has a large vertical and lateral stiffness. With the increase in speed, the accelerations of the bridge increase first and then decrease, and finally increase. The safe travel speed of the train through the bridge should be controlled within $80 \mathrm{~km} / \mathrm{h}$.

\section{Introduction}

In the process of new urbanization and "the Belt and Road" construction, the urban population has become more concentrated, the number of motor vehicles has increased dramatically, and the urban traffic congestion has become increasingly serious. So the biaxial rubber-tired LRT has been paid more and more attention as a powerful means to solve the urban traffic problem. The biaxial rubber-tired LRT began in France, and it now has a greater development in France, Canada, Mexico and Chile [1]. At present, many scholars have made a systematic study on the spatial calculation of box girder bridges. At present, many scholars have made a systematic study on the spatial calculation of box girder bridges [2-7]. However, there are few studies on the train-bridge system coupling vibration for biaxial rubber-tired LRT at home and abroad. And there is no mature spatial vibration theory and technical parameters about the box girder bridge for biaxial rubber-tired LRT. Therefore, it is necessary to analyze the dynamic characteristics of the box girder bridge for biaxial rubber-tired LRT.

Because there is no biaxial rubber-tired LRT line in China, the standard beam of Shanghai Pearl Line (namely, China's first urban viaduct steel-wheel LRT line) was selected as the object of study on the bridge structure for biaxial rubber-tired LRT in this paper. According to train-bridge system spatial vibration equation and Newmark- $\beta$ stepwise integration method, the train-bridge coupling spatial vibration analysis program was programmed with Compaq Visual Fortran Software, and the dynamic response of the box girder bridge for biaxial rubber-tired Light Rail Transit (LRT) was analyzed. This can provide a theoretical reference for the future construction of the biaxial rubber-tired LRT.

\section{Calculation parameters and spatial vibration equation of box girder bridge}

The standard beam of Shanghai Pearl Line is a simple-supported prestressed-concrete beam about 30m span. The beam uses single-box-double-cell box sections. Fig. 1 shows the cross section of the single-box-double-cell box girder. In addition to two side walls set at the side-support sections, 
three diaphragms are set at the mid-span sections with equal longitudinal distance, and the thickness of diaphragms and side walls $=0.2 \mathrm{~m}$. Material density, $\gamma=25 \mathrm{kN} / \mathrm{m}^{3}$. Poisson's ratio, $\mu=0.16$. The static elastic modulus, $\mathrm{E}=3.5 \times 107 \mathrm{kN} / \mathrm{m}^{2}$. In order to study its dynamic characteristics, the box girder bridge with 9 spans and $270 \mathrm{~m}$ length was calculated. The box girder was segregated by 4 elements and 5 nodes, so the box girder bridge with 9 spans was segregated by 36 elements and 45 nodes. The biaxial rubber-tired LRT train used MP89 French LRT train with rubber-tired bogies. The train consists of six rubber-tired LRT vehicles. The total mass of each vehicle body (full of passengers) is $43700 \mathrm{~kg}$, and the weight of the axis with a pair of wheels is $107.065 \mathrm{kN}$. Other parameters are found in References [1,8]. The train was initially on the first 3-spans box girders of the bridge, as shown in Fig.2. The entire calculation process was the train running process from the 4th span to the 9 th span.

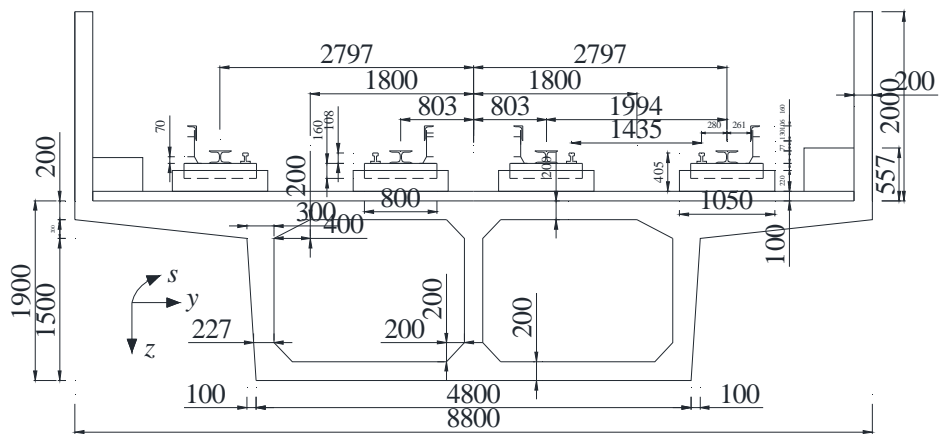

Fig. 1 Cross section of single-box-double-cell box girder (unit: $\mathrm{mm}$ )

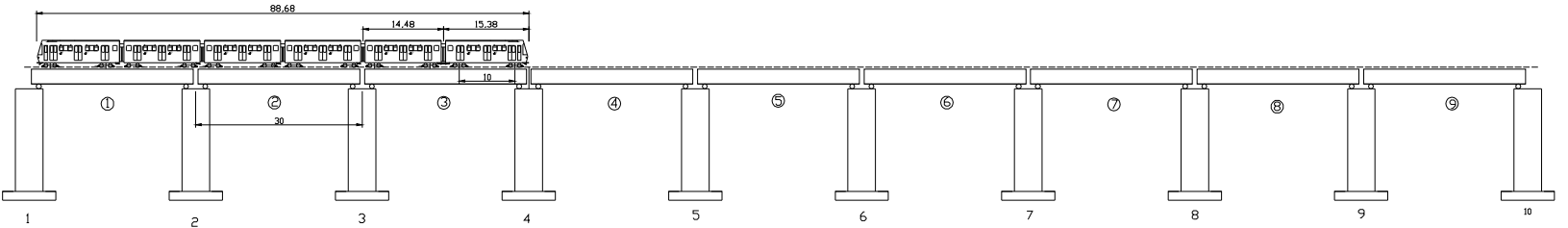

Fig.2 Initial position of the train

When the train passed through a box girder, the vehicles of the train passed in turn, and the number of vehicles on the box girder was variable. At time $t$, the total spatial-vibration potential energy of the train-bridge time-varying system for biaxial rubber-tired LRT is:

$$
\Pi=\Pi_{B}+\Pi_{V}=\Pi_{B}+\sum_{i=1}^{N} \Pi_{V i}
$$

where $\Pi_{B}=$ the vibration potential energy of bridge; $\prod_{V i}=$ the vibration potential energy of the ith vehicle.

The total stiffness matrix $[\mathrm{K}]$, total mass matrix $[\mathrm{M}]$, total damping matrix $[\mathrm{C}]$ and total load array $\{\mathrm{P}\}$ of the train-bridge system at time $\mathrm{t}$ can be obtained by potential energy variation principle and "sit in the right seat" principle [9]. The spatial vibration equation of the train-bridge time-varying system for biaxial rubber-tired LRT is expressed as:

$$
[M]\{\&\}+[C]\{\&\}+[K]\{\varepsilon\}=\{P\} \text {, }
$$

where $\{\varepsilon\},\{\varepsilon\}$, and $\{\& \varepsilon\}=$ displacement array, velocity array and acceleration array, respectively.

Referring to the sixth grade track irregularity PSD of U.S. railways, both a level track irregularity sample and a direction track irregularity sample were simulated by the trigonometric series method. The samples were used as the vibration excitation sources of the train-bridge spatial vibration analysis of biaxial rubber-tired LRT. The train-bridge time-varying system spatial vibration equation was solved by Newmark- $\beta$ stepwise integration method. The time step was taken for $0.1 \mathrm{~s}$ in the 
calculation. In order to simplify the calculation, the vibration displacement, speed and acceleration of the train-bridge time-varying system were all assumed to be zero when the train entered the bridge. In the calculation, the speed was $10 \sim 80 \mathrm{~km} / \mathrm{h}$. The system began to calculate when the train started to run at the same line condition as the 5 th box girder and from $30 \mathrm{~m}$ to the 5 th box girder. After the vibration of the vehicle bodies tended to be stable, the train began to run on the 5th box girder structure. The dynamic response data of the bridge were all presented from the 5th box girder.

\section{Numerical results and dynamic response analysis}

Displacement response analysis. Fig. 3 shows the relation of vertical bridge deflection and train speed. From the figure, it is clear that the vertical deflection of the bridge is less affected by the train speed. The vertical deflection fluctuates at different speeds, but it is in the range of $5.65 \mathrm{~mm}$ to $7.61 \mathrm{~mm}$. This is due to the vertical deflection of the bridge caused by the self-weight of the train. The maximum vertical deflection is $7.61 \mathrm{~mm}$, which is far less than the bridge deflection limit (23.1 $\mathrm{mm}$ ) specified in the bridge specification [10]. This indicates that the box girder bridge has sufficient vertical stiffness.

Fig.4 shows the relation of lateral bridge deflection and train speed. From the figure, it is clear that the lateral deflection of the bridge is less affected by the train speed. The lateral deflection of the bridge is generally flat, and it is in the range of $0.967 \mathrm{~mm}$ to $1.155 \mathrm{~mm}$. Due to the small influence of the weight of the train, the lateral deflection of the bridge at the same speed is much smaller than the vertical deflection. The maximum lateral deflection is $1.155 \mathrm{~mm}$, which is less than the bridge deflection limit $(3.33 \mathrm{~mm})$ specified in the bridge specification [10]. This indicates that the lateral stiffness of the box girder bridge can meet the requirements of the corresponding test specifications.

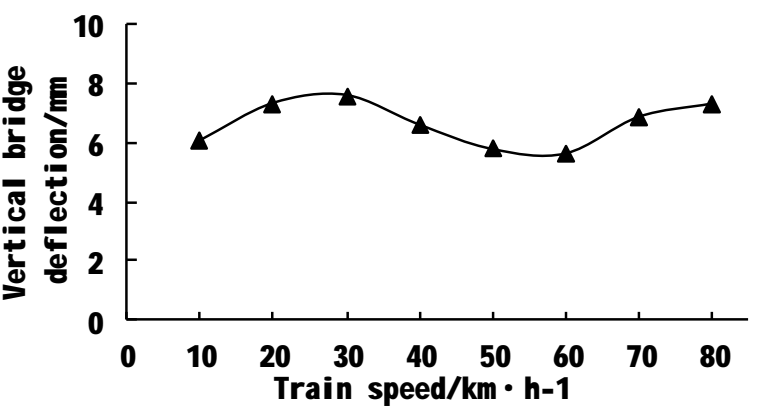

Fig. 3 Relation of vertical deflection and train speed

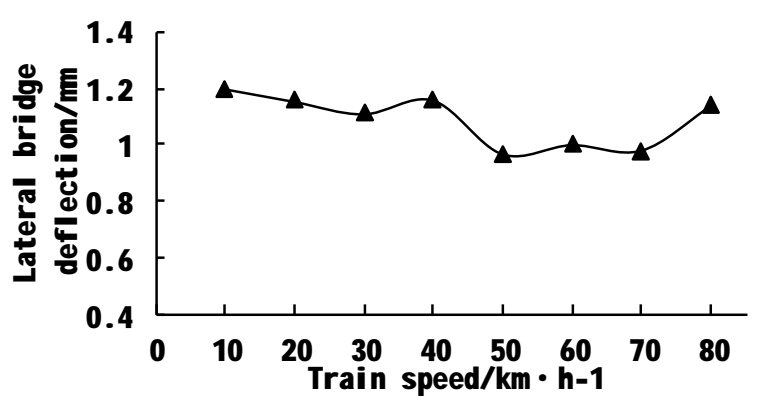

Fig. 4 Relation of lateral deflection and train speed

Acceleration response analysis. The vertical acceleration curves of mid-span bridge section was calculated, and the result is shown in Fig.5. It is clear from Fig.5 that the vertical acceleration of the bridge is greatly affected by the train speed, which increases with the increase of the train speed. Specifically, the vertical acceleration of the bridge increases first and then fluctuates with the increase in the train speed. Before the $30 \mathrm{~km} / \mathrm{h}$ speed, the increase trend of the vertical acceleration is gentle, and the maximum occurred at $50 \mathrm{~km} / \mathrm{h}$ speed. The maximum vertical acceleration of mid-span bridge section is $1.52 \mathrm{~m} / \mathrm{s}^{2}$, which is less than the vertical acceleration limit $\left(3.5 \mathrm{~m} / \mathrm{s}^{2}\right)$ of mid-span bridge proposed in China's Qinhuangdao-Shenyang Passenger Dedicated Bridge research and design. So these calculation results are safe.

The lateral acceleration curves of mid-span bridge section was calculated, and the result is shown in Fig.6. It is clear from Fig.6 that the lateral acceleration of the bridge is greatly affected by the train speed, which increases with the increase of the train speed. Specifically, with the increase in 
the train speed, the lateral acceleration of the bridge increases first and then decrease, and finally increase. The maximum occurred at $80 \mathrm{~km} / \mathrm{h}$ speed. In addition to the lateral acceleration at $50 \mathrm{~km} / \mathrm{h}$ and $80 \mathrm{~km} / \mathrm{h}$, the lateral acceleration of the bridge at each speed is less than the lateral acceleration limit $\left(1.4 \mathrm{~m} / \mathrm{s}^{2}\right)$ specified in the bridge specification [10]. It is concluded that the high lateral acceleration of the bridge at $50 \mathrm{~km} / \mathrm{h}$ is related to the difference between the theoretical and the actual stiffness and the track irregularities on the bridge. The cross-lateral acceleration of the bridge at $80 \mathrm{~km} / \mathrm{h}$ exceeds the limit of $1.4 \mathrm{~m} / \mathrm{s}^{2}$, which means that the safe travel speed of the train through the bridge should be controlled within $80 \mathrm{~km} / \mathrm{h}$.

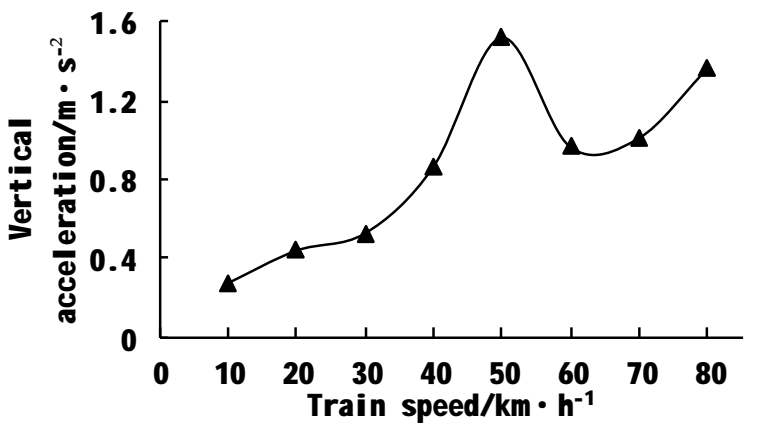

Fig. 5 Vertical acceleration curves of mid-span bridge section

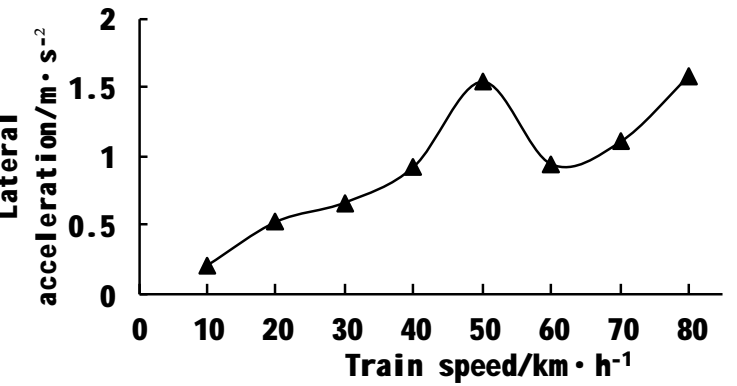

Fig. 6 Lateral acceleration curves of mid-span bridge section

Some of the acceleration responses are selected to analyze. Time history are shown in Figures 7 and 8. From these figures, it became clear that the curves are both the typical acceleration response curves of mid-span bridge section. At travel speed of $20 \mathrm{~km} / \mathrm{h}$, the maximum vertical acceleration of mid-span bridge section is $0.442 \mathrm{~m} / \mathrm{s}^{2}$. At travel speed of $80 \mathrm{~km} / \mathrm{h}$, the maximum lateral acceleration of mid-span bridge section is $1.58 \mathrm{~m} / \mathrm{s}^{2}$.

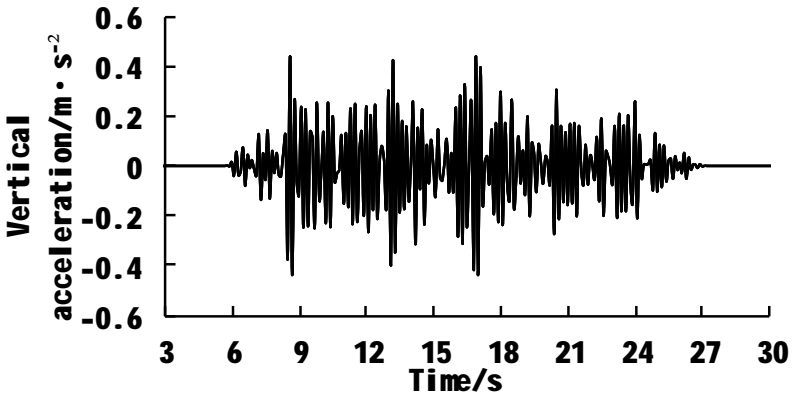

Fig. 7 Vertical acceleration response curve of mid-span bridge section at $20 \mathrm{~km} \cdot \mathrm{h}^{-1}$

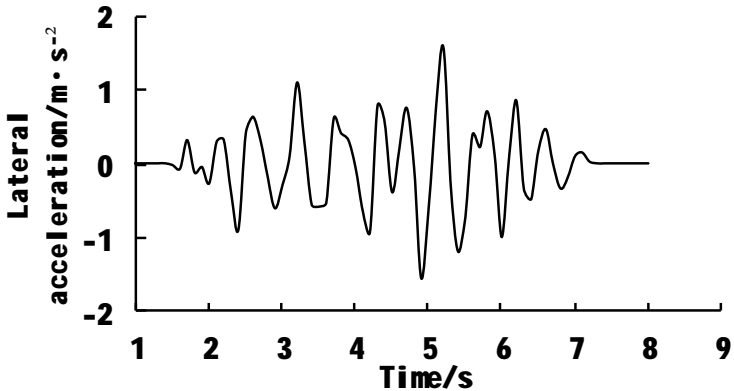

Fig. 8 Lateral acceleration response curve of mid-span bridge section at $80 \mathrm{~km} \cdot \mathrm{h}^{-1}$

\section{Conclusions}

The following points can be drawn based on the above studies.

(1) The vertical deflection and lateral deflection of the box-type bridge are less affected by the train speed. The vertical deflection fluctuates at different speeds, and the lateral deflection is generally flat. The vertical stiffness and lateral stiffness of the bridge can meet the requirements of the corresponding test specification.

(2) The vertical acceleration and lateral acceleration of the bridge are greatly influenced by the train speed. With the increase in speed, the accelerations of the bridge increase first and then decrease, and finally increase. The maximum vertical acceleration and lateral acceleration of the bridge occurred at $50 \mathrm{~km} / \mathrm{h}$ and $80 \mathrm{~km} / \mathrm{h}$ respectively.

(3) The safe travel speed of the train through the bridge should be controlled within $80 \mathrm{~km} / \mathrm{h}$. 


\section{Acknowledgement}

This work is financially supported by the Guangdong Provincial Natural Science Foundation of China (No. 2015A030310465) and the Guangdong Provincial Department of Education Excellence Talent Training Program (No. KA1603616).

\section{References:}

[1] Zhou Qingrun and Jin Feng: New urban rail transit (China Railway Publishing House, Beijing 2005) (In Chinese );

[2] Zhang J and Huo Y: Engineering Structures Vol. 31 (2009), p. 1648;

[3] Tsunashima, H: Vehicle System Dynamics Vol. 39(5) (2003), p. 365;

[4] Tan Guojin, Liu Ziyu and Wang Longlin: Journal of Vibration Engineering Vol. 29(5) (2016), p. 831 (In Chinese)

[5] Wang Shaoqin, Ma Qin and Xia He: Engineering Mechanics Vol. 33(12) (2016), p. 150 (In Chinese);

[6] Deng Jianliang, Wu Dingjun and Li Qi: Engineering Mechanics Vol. 29(10) (2012), p. 177 (In Chinese);

[7] Guo Xiangrong and Zeng Qingyuan: China Railway Science Vol. 22(4) (2001), p. 53 (In Chinese);

[8] Shi lili, Sun shouguang and Lu fengfeng: Journal of Northern Jiaotong University Vol. 25(4) (2001), p. 97 (In Chinese);

[9] Zeng Qingyuan and Yang Ping: Journal of the China Railway Society Vol. 8(2) (1986), p. 60 (In Chinese);

[10] Ministry of Railways of the People 's Republic of China: Code for Railway Bridge Verification (China Railway Publishing House, Beijing 2004) (In Chinese ); 